\title{
Emotional Masks: Linguoecological Aspect
}

\section{Solodovnikova Natalia Gennadievna ${ }^{1}$}

Associate Professor, Chair of linguistics

Volgograd State Socio-Pedagogical University, Volgograd, Russia.

(date of receiving: August, 2019; date of acceptance: December, 2019)

\begin{abstract}
Volgograd's school of linguistics of emotions (Head - Professor Victor Shakhovsky, the author of the theory of emotiveness), since 2010 has been developing ecological aspect of emotions through language. This means that the first Russian linguistic conception of emotions, formed in 1987, contemporarily is getting a new, ecofriendly, refraction. That is, the methodological framework of emotiology is considered from the standpoint of the ethics of emotions. It is known that between human emotions and their expression there are three types of relationships: emotion may be experienced and stay unexpressed; emotion may be experienced and expressed; there may be experienced one emotion and expressed a different one. The last case in the article is metaphorically called "emotional masks". In the article through the named metaphor is considered, with what emotion a person is included in the communication situation, and with what emotion might come out of it. Analyzed separately is the estimated sign of the emotions that communicants prefer to "mask". The "mask" of emotions is language. An attempt is made to assess the ecology of such a language.
\end{abstract}

Keywords: Emotion, Evaluative Sign, Ecology, Ethics, Emotive Mask.

1. E-mail: tommyboy22@mail.ru 
Issledovatel'skiy Zhurnal Russkogo Yazyka i Literatury, Vol.8, Issue 1, 2020, Pp: 121-137

DOI: $10.29252 /$ iarll.15.121

Article No.: 15.71.20201.121-137

\title{
Эмоциональные маски: лингвоэкологический аспект
}

\section{Солодовникова Наталия Геннадиевна ${ }^{1}$}

Доцент, Волгоградский государственный социально-педагогический университет, Волгоград, Россия.

(дата получения: август 2019 г.; дата принятия: декабрь 2019 г.)

\begin{abstract}
Аннотация
Волгоградской школой лингвистики эмоций, руководителем которой является автор теории эмотивности профессор Виктор Иванович Шаховский, с 2010 года разрабатывается экологический аспект оязыковлённых эмоций. Это означает, что первая в России лингвистическая концепция эмоций, сформированная в 1987 году, в современности получает новое, экологическое преломление. То есть методологическая база эмотиологии рассматривается с позиций этики эмоций. Известно, что между эмоциями человека и их выражением существует три типа взаимоотношений: эмоция может испытываться и не выражаться; эмоция может испытываться и выражаться; может испытываться одна эмоция и выражаться иная. Последний случай в статье предлагается метафорически называть «эмоциональными масками». В статье через указанную метафору рассматривается, с какими именно эмоциями человек входит в ситуацию общения, и с какими выходит из неё. Отдельно анализируется оценочный знак эмоций, которые общающиеся предпочитают «маскировать». «Маской» эмоций выступает язык. Предпринимается попытка оценить экологичность такого языка.
\end{abstract}

Ключевые слова: Эмоции, Оценочный Знак, Экологичность, Этичность, Эмоциональная Маска.

1. E-mail: tommyboy22@mail.ru 


\section{Введение}

Современная российская лингвистика эмоцуий (эмотиология) последовательно изучает следы личности в семантике слова и структурирует знания о категории эмотивности в языке. Названная область научного поиска исходит из того, что в человеке как биопсихосоциальном существе всё движимо эмоциями, так как они являются мотивационной основой всей его деятельности. Первая в России лингвистическая конщฺепцุия эмоций, основанная на единой методологии категоризации эмоций в лексикосемантической системе языка, была разработана проф. В.И. Шаховским в 1987 г. В 2008 г. результаты работы над проблемой «эмоции в языке» оформились в лингвистическую теорию эмоций. К 2010 г. эмотиология получила экологическое преломление: у неё родилась эмотивная лингвоэкология (Шаховский 2008; 2016; Шаховский, Солодовникова 2010).

Эмотивный подход $к$ языку состоит в соединении философского понимания эмоций как формы оценочного отражения действительности с психологическим пониманием эмоций как особого психического пласта, надстраивающегося над познавательным образом. Через эмоции сам язык становится ключом к изучению человека: он номинирует, категоризует, классифицирует, структурирует, комментирует, эксплицирует, имплицирует, моделирует эмоции и формирует эмоциональную картину мира представителей той или иной лингвокультуры.

В настоящее время в Волгоградском государственном педагогическом университете в Институте иностранных языков В.И. Шаховским и его учениками и коллегами по кафедре языкознания ведётся работа по описанию сути эколого-эмотивной коммуникативной компетенции, которая подразумевает способность порождать эмотивно уместные (экологичные) тексты и адекватно воспринимать личностные эмоциональные доминанты других текстов как отражение иноконцептосфер и инокультур. Проблемы эмотиологии получают 
всё большее экологическое переосмысление, чтобы у общающихся укреплялся вектор экологичности в процессе обмена эмоциями в языке.

Одним из интересующих эмотиологию направлений развития можно считать экологию эмоций. В контексте тематики данной статьи эту проблему можно сформулировать следующим образом: какие из актуально испытываемых эмоций коммуниканты избирательно эксплицируют, какие предпочитают скрывать, какие подменяют на уровне выражения, за какими предпочитают скрываться. Всё перечисленное выше, по нашему мнению, метафорически можно назвать содержанием эмоциональных масок. В данной статье эмоциональные маски не рассматриваются через понятия неискренности, лицемерия, лжи и т.п. Названный подход может быть одной из перспектив исследования. Мы обращаем внимание только на эмоциональное наполнение масок в экологическом аспекте, что сопряжено с понятиями этики, эстетики, вежливости, стилистики и пр. В своих исследованиях мы исходим из экоцентрического понимания природы человеческих эмоций и на текущем этапе исключаем неэкологичность из интересующей нас проблематики. Поэтому подбираются контексты, в которых эмоциональные маски являются экологическим выходом из конфликтной ситуации общения. В статье через указанную метафору рассматривается, с какими именно эмоциями общающиеся вступают в ситуацию общения, с какими покидают её. Отдельно анализируется оценочный знак эмоций, на которые общающиеся предпочитают набросить языковую маску этичности.

\section{Основная часть}

В настоящее время, как уже отмечалось выше, многие интересующие эмотиологию вопросы пересматривается с экологических позиций, потому что уже давно осознаётся необходимость перехода от антропоцентрического мышления к экоцентрическому. 
Экологи всего мира ориентируют людей если не на восполнение, то хотя бы на сбережение природных ресурсов. К защитникам природы присоединяется всё больше представителей эко-ориентированных областей знания. Активно развиваются такие отрасли, как экопсихология, экопедагогика, экофилософия, экомедицина и др. Их глобальная цель состоит в осуществлении экоцентрического поворота в сознании современного человека. Вероятно, именно названным стремлением эко-специалистов можно объяснить экологизаџию гуманитарной науки. Термины методика экологического образования, эколого-педагогическая деятельность, экологическая культура, эколого-развивающая среда, экологически ориентированная личность, эколого-педагогическая подготовка, экологическая воспитанность и обученность и другие ассоциируются уже не с природоведением, а с человековедением. Присоединяются к экологам природы и экологи коммуникации.

Известно, что осознание необходимости экологизащии жизни появляется у человека тогда, когда им ощущается нарушение экологического баланса в важнейших сферах жизни. Актуализировавшийся сегодня экологический аспект лингвистических исследований связан с потребностью общества в восстановлении экологического равновесия в сфере речевой коммуникации, нарушения в которой ощущаются носителями языка и фиксируются учёными.

Заметным становится стремление к экологическому конструктивизму такой науки, как эмотивная лингвоэкология.

Родившись из сплава экологии, валеологии и эмотивной лингвистики, эмотивная лингвоэкология занялась изучением здоровья эмоций человека и использованием эмотивно здорового языка.

В парадигме эмотивной лингвоэкологии эмоциональность рассматривается в качестве важнейшего регулятора экологичности коммуникации. 
Эмотивная лингвистика является основой методологической базы эмотивной лингвоэколологии, поскольку последняя пользуется методом эмотивного анализа коммуникативных ситуаций в качестве основного, в сравнении с её ориентацией на достижения других наук. Соединение эмотивной лингвистики с валеологией обеспечивает признание экологии человека в коммуникации, т.е. сбережение его эмоций и языка, главным объектом эмотивной лингвоэкологии. И если сохранение и совершенствование языка - общая задача всех лингвоэкологов, то экология (сохранение здоровья) эмоций человека в коммуникации через использование эмотивно здорового (экологичного) языка - это предметная область экоэмотиологов.

Весь мир осознаёт глобальные экологические изменения с непредсказуемыми последствиями, происходящие не только в природе, но и в социуме. Именно поэтому большое внимание необходимо уделять человеческому фактору в языке, то есть эмоциям человека. Существует острая необходимость повысить уровень знаний людей и изменить их отношение к природе и самому себе. Поэтому со всей очевидностью встал вопрос о всеобщем экологическом образовании. Важнейшим фактором решения экологических проблем должно стать глобальное воспитание, которое поставит экологические вопросы в центр всех учебных программ. Если не внушить человеку простую и убедительную мысль, что люди - это часть природы, наше выживание, защита окружающей среды могут оказаться лишь абстрактными понятиями.

Введение экологического аспекта в эмотиологию и выделение эмотивной эколингвистики произошло совсем недавно, и это вызывает множество вопросов и сомнений у представителей смежных областей знания. Доминантой лингвоэкологов является благоговейное отношение к языку и речи. При этом доминантой экоэмотиологов, по нашему мнению, является 
возвышение человека в коммуникации. С этой точки зрения успешная коммуникация всегда экологична.

Это означает, что: 1) адресант и адресат реализовали все поставленные в конкретной эмоциональной ситуации цели; 2) эта реализация произошла через использование этичных эмотивов; 3) после окончания общения все его участники почувствовали себя лучше, чем до него. Выполнение этих трёх условий зависит от позитивности, эмоциональности, эмотивности и эмоциогенности: 1) изначальный эмоциональный импульс должен быть положительным (искренняя доброжелательность); 2) языковая реализация должна быть этичной и эстетичной (отбор и использование положительнооценочных эмотивов); 3) у коммуникативного партнёра должны возникнуть ответные положительные эмоции.

Данные положения, как правило, вызывают вопрос о том, всегда ли экологичны только положительные эмоции. Мы полагаем, что нет (вспомним случаи праведного гнева и благородной ярости). В основе экологичного общения лежит искренняя доброжелательность и интенция возвышения адресата. Однако искренние, справедливо возникшие отрицательные эмоции имеют право называться экологичными. Но искренние, справедливые эмоции, например, группы гнева, должны получать этичную (вежливую) упаковку. Если эмотивы отвечают условию этичности, а результатом общения в той или ситуации становится то, что все его участники расходятся, почувствовав себя лучше (позитивная эмоциогенность), такое общение можно назвать экологичным.

В коммуникации основную роль играет человеческий фактор - это экологическое мышление, экологическое сознание, экологическая культура людей и экологический интеллект. Введение экологического аспекта в лингвистику эмоций отвечает современным тенденциям науки. И лингвистическая теория эмоций В.И. Шаховского, как мы уже обосновывали в 
предыдущих работах (Солодовникова 2013), представляет собой конструктивную попытку формирования экоцентрического сознания через развитие экологической компетенции коммуникативной личности.

Экологическая компетенция коммуникативной личности (а человек, с точки зрения лингвистики эмоций, в первую очередь, homo sentiens) состоит в умении обращаться с эмоциями, в том числе, с эмоциями в языке. Следовательно, необходимо специиально рассказывать об экологии эмоций и обучать осторожному обращению с ними. Необходимо давать современным коммуникантам знание о потенциальных эмоциогенных рисках, напоминать о параметрах экологичного общения (вежливость, толерантность, уважение, сдерживание негативных эмоций, поощрение, положительное оценивание, равные коммуникативные права и др.). Формулой экологичности предлагаем считать искреннюю доброжелательность в этичной (а)вербальной упаковке. Если условия искренности, доброжелательности, справедливости и этичности в выражении как позитивных, так и негативных эмоций выдерживаются, общение можно считать экологичным.

При экоцентрическом подходе высшую ценность представляет гармоничное развитие человека и природы. Экоцентрический поворот позволяет говорить о том, что через эмоции нужно рассматривать язык как ключ к изучению человека уже как части природы. Необходимо помнить, что эмоция порождает ситуацию (и наоборот). Добавим сюда знание об экологии эмоций: экологичная эмоция порождает экологичную ситуацию (и наоборот).

Правило экологического этикета подразумевает следующую формулу: не позволять себе плохое настроение, т.к. это неприлично и вредно для здоровья.

Человек не может испытывать только положительные эмоции. Для психологического здоровья личности необходима вся гамма эмоций (Подольская www). С эколингвистических позиций необходимо оценивать их проявления. 
Это предполагает поиск экологичных масок эмоциональности, а также обучение всех общающихся экологичному языку.

Считаем, что обучать этому необходимо специально, начиная с семьи, продолжая в школе, заканчивая в университете.

Выбор эмоциональной маски всегда будет зависеть от внутреннего экологического цензора, который воспитуем и самовоспитуем.

Умение выбрать экологичную эмоциональную маску напрямую зависит от знания об оценочном знаке эмоции. Осознание того, что эмоция - это всегда биохимическое состояние нашего организма, повышает степень ответственности общающихся друг перед другом. Если без специальной подготовки человек не может управлять эмоциональным переживанием, то управлению выражением эмоций можно научиться. Ведь выражение эмоций это уровень вербалики. Вербалика состоит из стилистики, т.е. выбора и комбинаторики языковых единиц. Знание об оценочном потенциале эмотивной семантики слов регулирует этичность (экологичность) сказанного.

Слушателям разработанного проф. В.И. Шаховским курса «Лингвокультурология эмоций», который читается в Институте иностранных языков Волгоградского государственного педагогического университета, предоставляется возможность научиться экологическому пониманию эмоций.

Проф. В.И. Шаховский всегда говорит своим слушателям, что художественная литература - это депозитарий человеческих эмоций. На примере многоаспектного эмотивного и экологического анализа короткого рассказа на английском языке С. Барстоу «Ярость» он показывает своим ученикам применение знаний об эмоциях в языке. Этот текст является уникальной иллюстрацией к лингвистической теории эмоций, поскольку в изображенной коммуникативной эмоциональной ситуации супружеской ссоры каждый читатель может найти примеры ко всем основным положениям эмотиологии в экологическом аспекте. 
Автор данной статьи продолжает читать разработанный В.И. Шаховским курс, но уже в не аспекте лингвокультурологии, а экологии эмоций. Сохраняя традицию, заложенную В.И. Шаховским, мы пересматриваем ставшие уже классическими проблемы лингвистики эмоций в ином разрезе и далее по тексту статьи приводим собственные умозаключения. Экологический аспект эмоций стал новым витком в прочтении и названного выше теоретического курса, и художественного текста. Как и любое талантливое художественное произведение, этот текст открывает множество возможностей для интерпретации, т.к. многослоен и соткан из ярких и образных стилистических средств и приёмов. Текст - живой, а каждый читатель - всегда его соавтор (Эко 2005).

Отражённая в тексте ситуация - метафорична, потому что типична. Жена отомстила мужу, лишив его любимого хобби.

Текст озаглавлен словом «Ярость». Ярость - мотив жены в её мести мужу, ярость - возможная реакция мужа на поступок жены. Поступок, совершённый в гневе, как известно, иногда невозможно исправить.

Кластеры эмоций, сложившиеся в ярость обоих персонажей, прописаны детально. Толстый канат ярости сплетён из ревности, злости, обиды, зависти, отчаяния, негодования, разочарования и других эмоций группы гнева.

Текст с открытым финалом предлагает каждому читателю найти выход из сложившейся ситуации.

Наблюдая за эмоциями обоих персонажей, слушатели курса учатся находить выход из конфликта, потому что они ориентируются на экологичность.

Анализируя развитие конфликта, на каждой его стадии студентам предлагается «отредактировать» поведение поссорившихся супругов, исправить то, что в их отношениях пошло не так. 
Многоаспектный эмотивный анализ вербалики и авербалики персонажей позволяет обнаружить типы эмоционально-вербальной асимметрии: эмоция может испытываться и не выражаться; эмоция может испытываться и выражаться; может испытываться одна эмоция и выражаться иная. Последний случай в статье, как оговаривалось выше, предлагается метафорически называть «эмоциональными масками».

Приведём пример из текста, который, по нашему мнению, хорошо иллюстрирует суть эмоциональной маски, которую считаем в данном контексте экологичной. Подчёркиванием выделены истинные и скрытые эмоции персонажа.

On Sunday morning she was shaking a mat in the yard when her nextdoor neighbour spoke to her over the fence.

'Did you get to the Palace this week, then, Mrs. Fletcher?' Mrs. Sykes asked her. 'Oh, but you did miss a treat. All about the early Christians and the cloak 'at Jesus wore on the Cross. Lovely, it was, and ever so sad.'

'I wanted to see it,' Mrs. Fletcher said, 'but Jim didn't get back from Cressley till late. His rabbits $y^{\prime} k n o w . '$ She felt a strong desire to abuse him in her talk, but pride held her tongue. It was bad enough his being as he was without the shame of everyone knowing it.

'Oh, aye, they had a show, didn't they?' Mrs. Sykes said. 'Aye, I saw him in the bus station afterwards. He was talking to a woman I took to be your sister

Mrs. Fletcher shot the other woman a look. What was she up to? She knew very well that her sister had lived down south these last twelve months. Her cheeks flamed suddenly and she turned her back on her neighbour and went into the house.

Приведём художественный перевод данного фрагмента. 
Утром в воскресенье она выбивала коврик во дворе, когда соседка окликнула ее через забор:

- Ну что, миссис Флечер, ходили вчера в Палас? - спросила миссис Сайкс. - Ох, что за картина, жаль, что пропустили. Там все ранние христиане и Иисусов плащ, в котором он был на кресте. Чудо как хорошо, и уж до того печально.

- Хотела посмотреть, - сказала миссис Флечер, - да вот Джим из Кресли поздно вернулся. Все с кроликами своими возится. - Ей страстно хотелось выбранить его, но гордость заставила придержать язык. И так не мужик, а чёрт-те что, не хватало еще перед соседями срамиться рассказывать.

- A, ну да, у них же там выставка была, - сказала миссис Сайкс. Видала я его потом на автовокзале. Он разговаривал с женщиной, вроде сестра вама.

Миссис Флечер пронзила соседку взглядом. Чего это она? Знает же отлично, что ее сестра уже год, как живет на юге. Миссис Флечер вспыхнула, повернулась и пошла в дом (Барстоу 2001).

Из данного примера очевидно, что реплика соседки вызвала у главной героини кластер негативных эмоций (стыд, негодование, возмущение, досаду, разочарование, гнев), которые она предпочла сдержать (т.е. не выразить вербально). Вместо реальных эмоций она из гордости предпочла промолчать.

Вертикальный контекст истории главной героини открывает читателю её натуру. Как известно, гнев - одна из эмоций, которые хуже всего поддаются контролю. Нужно отдать должное вспыльчивой и ревнивой героине рассказа, что она смогла не поддаться импульсу и скрылась за маской молчания в явно травмирующей для неё ситуации неприятного и унизительного разговора с соседкой. 
Ранее мы отмечали, что экологичной, по нашему мнению, можно считать такую коммуникацию, в которой: 1) адресант и адресат реализовали все поставленные в конкретной эмоциональной ситуации цели (в разговоре с соседкой, которая явно провоцировала главную героиню, последней удалось сдержать изначальный импульс пожаловаться на мужа, что позволило ей сохранить чувство собственного достоинства. В конфликтной ситуации удержаться от импульсивных ответов - одна из самых сложных задач. Вспомним в этой связи высказывание Расула Гамзатова: «Воистину тот славен и велик, кто в гневе удержал язык» (Гамзатов www). Соседка сознательно реализовала неэкологичную задачу поддразнить и уколоть главную героиню, но той удалось сохранить лицо.); 2) эта реализация произошла через использование этичных эмотивов (вербалика главной героини ничем не выдаёт её разочарования и обиды на мужа); 3) после окончания общения все его участники почувствовали себя лучше, чем до него (главная героиня почувствовала себя плохо, но ещё хуже для неё было бы сделать очевидными для посторонних глаз их проблемы с мужем).

Легко быть экологичным, когда обе общающиеся стороны стремятся к позитивности эмоциональности, эмотивности и эмоциогенности. Когда одна из сторон намеренно ведёт себя конфликтно (провокации, игнорирование, неуважение и т.д.), может произойти «расшатывание» изначального положительного эмоционального импульса и искренней доброжелательности (главная героиня, выбивая коврик, не намеревалась ссориться с соседкой). После слов соседки у главной героини уже не могли возникнуть ответные положительные эмоции. Её экологичность оказалась разбалансированной. Однако в явно стрессовой для неё ситуации её языковая реализация эмоций осталась этичной на уровне отбора и использования положительнооценочных эмотивов, которые в тексте примера выделены подчёркиванием. Когда у главной героини не осталось сил противостоять нападкам соседки, она скрыла свои эмоции за маской молчания. 
Выше мы отмечали, что в данной статье будет рассматриваться, с какими именно эмоциями общающиеся вступают в ситуацию общения, с какими покидают её. Отдельно планировалось проанализировать оценочный знак эмоций, на которые общающиеся предпочитают набросить языковую маску этичности.

Разговор с соседкой о муже оказался для главной героини неприятной неожиданностью. Она уже была расстроена ссорой с мужем, но утром вышла во двор по бытовой необходимости, никак не ожидая нападок со стороны соседки, без какого бы то ни было намерения судачить о супруге с посторонними лицами и выносить сор из избы. Она также не была настроена против соседки. Т.е. в данной ситуации эмоции главной героини можно назвать экологичными.

Соседка сознательно провоцировала неприятные ощущения у главной героини. После этой встречи последняя явно получила неэкологичный импульс и испытала несколько отрицательных эмоций, которые позже, уйдя от соседских глаз, выплеснула в новой ссоре с мужем. Однако именно на эти эмоции она набросила защитную маску гордости, выдержав этический принцип не обсуждать мужа с чужими людьми. И укрепила её молчанием.

Ранее, в одной из своих предыдущих статей, мы пытались обосновать, что молчание является одним из самых сильных семиотических знаков (Солодовникова 2017). Молчанье - щич от многих бед (Хайям www) и может стать одной из самых сильных по степени экологичности эмоциональных масок, кроме тех случаев, когда оно - заговор равнодуиных (Ясенский www).

\section{Заключение}

В данной статье мы попытались проиллюстрировать, что эмоциональная маска может выступить способом защиты от неэкологичного поведения одного из общающихся. Эмоциональная маска спасает в ситуациях, когда есть 
асимметрия между тем, какая эмоция испытывается, и тем, какая эмоция выражается. Это противоречие может быть обусловлено коммуникативной опасностью нарушения этикета или собственной экологии эмоций. Эмоциональная маска этичности или молчания - возможность экологического ухода и выхода из надвигающегося конфликта.

Эмоциональная маска не обеспечивает полную защиту от отрицательного эмоционального импульса, исходящего от провоцирующего конфликт иного участника общения, но позволяет уйти от полной уязвимости, которая возникает при «потере лица».

У эмоциональной маски можно выделить несколько функций: номинирующую, категоризующую, классифицирующую, структурирующую, комментирующую, эксплицирующую, имплицирующую, моделирующую эмоции и формирующую эмоциональную картину мира представителей той или иной лингвокультуры и иные. Ведущей можно назвать коммуникативную. Анализ функций эмоциональных масок является одним из перспективных направлений развития экологического понимания эмоций в языке.

\section{Литература}

1- Барстоу С. (2001) Ярость // Московские новости. № 3.

2- Гамзатов Р. (2018) Жемчужины мысли. - Режим доступа: ttp://www.inpearls.ru/author/rasul+gamzatov

3- Подольская О. (2018) Надо ли быть позитивным человеком. - Режим доступа: https://lady.mail.ru/article/485776-nado-li-byt-pozitivnym-chelovekom/

4- Солодовникова Н.Г. (2013) Авторский курс проф. В.И. Шаховского «Язык и эмоции»: формирование эмотивной компетенции коммуникативной личности // Человек в коммуникации: от категоризации эмоций к эмотивной лингвистике: Сб. научн. трудов, посвященный 75-летию профессора В.И. Шаховского. Волгоград : Волгоградское научное издательство.

5- Солодовникова Н.Г. (2017) Эмоциональная поливалентность нулевых знаков 8 лингвоэкологическом аспекте (на примере слова молчание) // Мир лингвистики и коммуникации: электронный научный журнал. № 1 (47). 
6- Хайям О. (2018) Жемчужины мысли. - Режим доступа: http://www.inpearls.ru/ author/7898

7- Шаховский В.И. (2008) Категоризаџия эмоџий в лексико-семантической системе языка. Изд. 2-е, испр. и доп. М.: Изд-во «ЛКИ».

8- Шаховский В.И. (2016) Диссонанс экологичности в коммуникативном круге: человек, язык, эмоции (монография). - Волгоград: Изд-во «ИП Поликарпов И.Л.».

9- Шаховский В.И., Солодовникова Н.Г. (2010) Лингвоэкология: объект, предмет и задачи // Русский язык, литература, культура в школе и вузе. № 1 (31).

10- Эко У. (2005) Роль читателя. Исследования по семиотике текста / пер. с англ. и итал. С.Д. Серебряного. - СПб.: Симпозиум.

11- Ясенский Б. (2018) Заговор равнодушных. - Режим доступа: http://modernlib.ru/ books/yasenskiy_bruno/zagovor_ravnodushnih/read

\section{Bibliography}

1- Barstou S. (2001) Jarost' // Moskovskie novosti. № 3.

2- Gamzatov R. (2018) Zhemchuzhiny mysli. - Rezhim dostupa: ttp://www.inpearls.ru/ author/rasul+gamzatov

3- Podol'skaja O. (2018) Nado li byt' pozitivnym chelovekom. - Rezhim dostupa: https://ady.mail.ru/article/485776-nado-li-byt-pozitivnym-chelovekom/

4- Solodovnikova N.G. (2013) Avtorskij kurs prof. V.I. Shahovskogo «Jazyk $i$ jemocii»: formirovanie jemotivnoj kompetencii kommunikativnoj lichnosti // Chelovek v kommunikacii: ot kategorizacii jemocij k jemotivnoj lingvistike: Sb. nauchn. trudov, posvjashhennyj 75-letiju professora V.I. Shahovskogo. Volgograd : Volgogradskoe nauchnoe izdatel'stvo.

5- Solodovnikova N.G. (2017) Jemocional'naja polivalentnost' nulevyh znakov $v$ lingvojekologicheskom aspekte (na primere slova molchanie) // Mir lingvistiki i kommunikacii: jelektronnyj nauchnyj zhurnal. № 1 (47).

6- Hajjam O. (2018) Zhemchuzhiny mysli. - Rezhim dostupa: http://www.inpearls.ru/ author/7898

7- Shahovskij V.I. (2008) Kategorizacija jemocij v leksiko-semanticheskoj sisteme jazyka. Izd. 2-e, ispr. i dop. M.: Izd-vo «LKI».

8- Shahovskij V.I. (2016) Dissonans jekologichnosti v kommunikativnom kruge: chelovek, jazyk, jemocii (monografija). - Volgograd: Izd-vo «IP Polikarpov I.L.».

9- Shahovskij V.I., Solodovnikova N.G. (2010) Lingvojekologija: ob\#ekt, predmet $i$ zadachi // Russkij jazyk, literatura, kul'tura v shkole i vuze. № 1 (31). 
10- Jeko U. (2005) Rol' chitatelja. Issledovanija po semiotike teksta / per. s angl. i ital. S.D. Serebrjanogo. - SPb.: Simpozium.

11- Jasenskij B. (2018) Zagovor ravnodushnyh - Rezhim dostupa: http://modernlib.ru/ books/yasenskiy_bruno/zagovor_ravnodushnih/read

HOW TO CITE THIS ARTICLE

Солодовникова Н. Г. (2020). Emotional Masks:

Linguoecological Aspect. Issledovatel'skiy Zhurnal

Russkogo Yazyka I Literatury, 8(1), 121-137.

DOI: $10.29252 /$ iarll.15.121

URL: http://www.journaliarll.ir/index.php/iarll/article/view/112 


\title{
ماسكهاى عاطفى: بُعد اكولوزيك زبان
}

\author{
ناتاليا گنادييونا سالادوونيكووا' \\ دانشيار، دانشكاه دولتى علوم اجتماعى و يداكوزيكى ولكَو كراد،

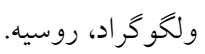

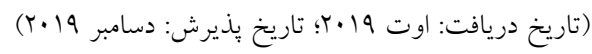

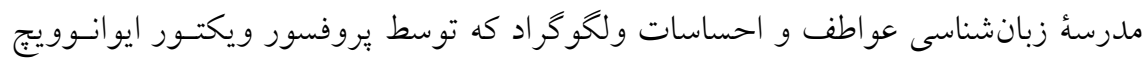

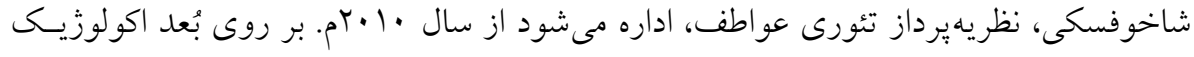

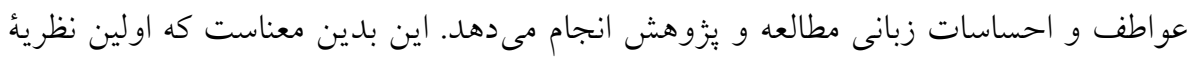

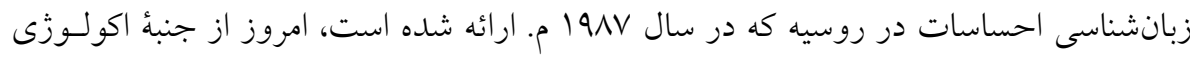

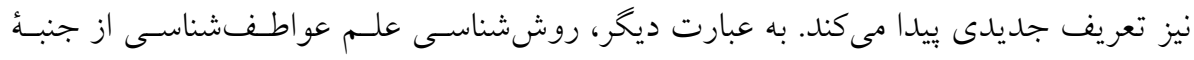

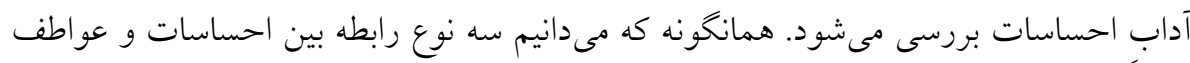

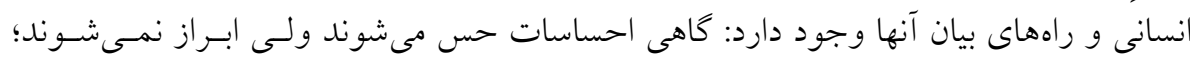

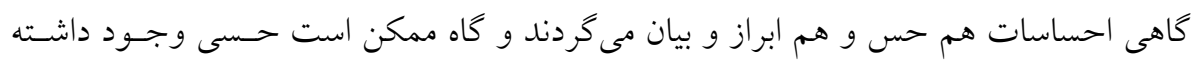

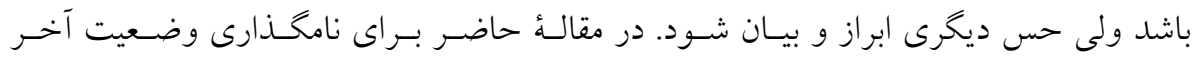

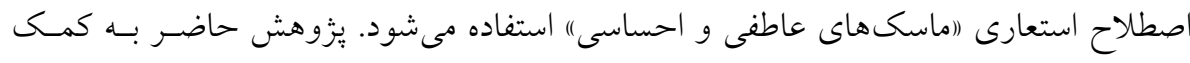

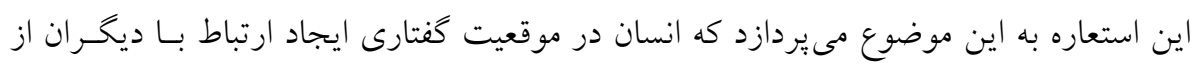

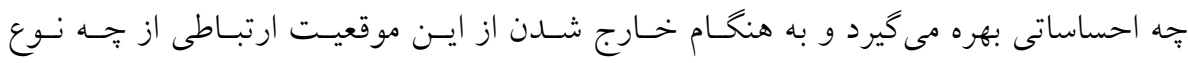

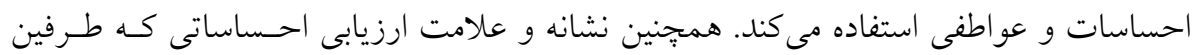

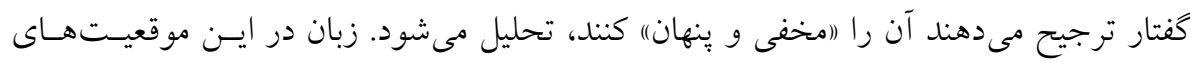

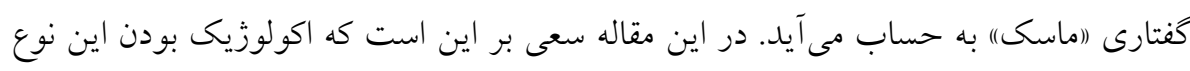
زبان ارزيابى شود.

وازگكان كليدى: احساسات، علامت ارزيابى، اكولوزيك بودن، جنبة اخلاقى، ماسك عاطفى. 